\title{
HOW DIFFERENT REFORESTATION APPROACHES AFFECT RED SOIL PROPERTIES IN SOUTHERN CHINA
}

\author{
H. ZHENG, ${ }^{1}$ Z. Y. OUYANG, ${ }^{1}{ }^{*}$ X. K. WANG,${ }^{1}$ H. MIAO, ${ }^{1}$ T. Q. ZHAO ${ }^{1}$ AND T. B. PENG $^{2}$ \\ ${ }^{1}$ Key Lab of Systems Ecology, Research Center for Eco-Environmental Sciences, Chinese Academy of Sciences, Beijing 100085, China \\ ${ }^{2}$ Institute of Subtropical Agriculture, Chinese Academy of Science, Changsha 410125, China \\ Received 15 January 2004; Revised 5 July 2004; Accepted 20 July 2004
}

\begin{abstract}
Significant differences were found in soil physicochemical and biological effects between various forest restoration approaches of a hilly red-soil region, southern China. Soil quality was the highest in natural secondary forest (0.95), while in sites revegetated with tea-oil camellia (Camellia oleifera), Chinese fir (Cunninghamia lanceolata) and slash pine (Pinus elliottii) and control sites, integrated soil quality indices were $0.68,0.55,0.36$ and 0.04 respectively. The lower soil quality of plantations and controls resulted from increased disruption of soil physical structure, lower quality litter fall, lower litter fall production, reduction in microbial biomass, decline of microbial function and loss of soil nutrients due to periodically artificial tending and accelerated soil erosion. Improvement in soil physicochemical properties and enhanced soil microbial function at a natural secondary forest site demonstrated the inherent restoration of these soils. Hence, natural restoration, as well as reducing human disturbance, is a better approach to improving soil properties than returning farmland to planted woodlands. Copyright (C) 2005 John Wiley \& Sons, Ltd.
\end{abstract}

KEY WORDS: plantation; natural restoration; soil quality index; China

\section{INTRODUCTION}

The former densly forested hilly red soil region of southern China, which covers $2.18 \times 10^{6} \mathrm{~km}^{2}$, including 10 provinces, is now known as the 'red desert of southern China' (Zhao, 2002). The effects of different agricultural uses on soil properties after deforestation have received much attention. Recent policies of 'returning farmland to forest' in the mid-lower reaches of the Yangtze River resulted in replantation of farmlands with slash pine, Chinese fir, tea-oil camellia, and so on. In a few areas fallow farmlands were left to natural succession into secondary forest. However, restoration of biological, chemical and physical soil quality was not studied frequently (Xie, 2002). The objectives of the present study were to: (1) compare soil physicochemical and biological properties in response to different forest restoration approaches, expressed in terms of soil quality index; and (2) determine the most suitable and sustainable forest restoration approaches.

\section{MATERIALS AND METHODS}

\section{Description of the Study Area}

The study was conducted at the Ecological Benefit Monitoring Station of the Yangtze River Protection Forestthe hilly red soil region of southern Hunan Province, which is located in the small valley of Changchong Village,

${ }^{*}$ Correspondence to: Z. Y. Ouyang, Key Lab of Systems Ecology, Research Center for Eco-Environmental Sciences, Chinese Academy of Sciences, PO Box 2871, Beijing 100085, China. E-mail: zyouyang@mail.rcees.ac.cn

Contract/grant sponsor: National Key Basic Research Program, China; contract/grant number: G2000046807.

Contract/grant sponsor: National Natural Science Foundation of China; contract/grant number: 30230090.

Contract/grant sponsor: Knowledge Innovation Project of the Chinese Academy of Sciences, China; contract/grant number: KZCX2-405. 
Langlong Country, Hengyang County of Hunan Province $\left(27^{\circ} 05^{\prime} \mathrm{N}, 112^{\circ} 18^{\prime} \mathrm{E}\right)$. Elevation of the research sites ranges from 86 to $147 \mathrm{~m}$ above sea-level. The climate of the area is subtropical humid monsoon. The mean annual temperature is $17.9^{\circ} \mathrm{C}$, and the mean annual rainfall is $1237 \mathrm{~mm}$. The soil is red soil formed from the same parent material as arenaceous shale, which is widely distributed in Southern China. The soil is classified in China Soil Taxonomy as fine loamy, hyperthermic, acidic, Udic Cambisols. Up till 1989, nearly every year people living in the surrounding villages encroached on and exploited the forests through clear felling without taking any soil conservation measures. Regeneration of existing residual vegetation on clear-felled and degraded reforested lands is hampered and wildlife has almost disappeared.

\section{Soil Sampling and Processing}

With the introduction, since 1989, of a policy of 'returning the farmland to forest', four forest restoration approaches were chosen, related to representative forest types in southern China in 1989. Before revegetation, the lands were shaped into a horizontal belt.

(1) Slash pine (Pinus elliottii) plantation (13 years growth) (SPP). The slope of the study site was 25 degrees. It was tended every 2-3 years. The way of tending was to loosen the soil all over the ground and clear the grasses and shrubs in order to keep the pure forest of slash pine. The last tending was in 1998.

(2) Chinese fir (Cunninghamia lanceolata) plantation (13 years growth) (CFP). The slope of the study site was 25 degrees. It was tended every 2-3 years. The way of tending was the same as that of the slash pine plantation. The last tending was in 1998.

(3) Tea-oil camellia (Camellia oleifera) plantation (13 years growth) (TCP). The slope of the study site was 18 degrees. After artificial plantation, little management and disturbance occurred.

(4) Natural secondary forest (NSF). The slope of the study site was 25 degrees. Since 1989, the land has been left to natural reforestation (13 years), and no disturbance has occurred. Many conifers Pinus elliottii, $P$. massoniana and hardwoods Quercus aliena, Q. fabri, and Q. glauca developed, with prolific understory vegetation.

(5) In addition, a badlands area adjacent to a slash pine plantation was chosen as a control (CK). The slope of the study site was 25 degrees. At this site, local people fell firewood and graze all the time. Due to long-term over-exploitation and serious soil erosion, the vegetation coverage of some grass species, such as Eragrostis pilosa, Imperata cylindrical, and Miscanthus sacchariflorus, was less than 20 per cent.

In July 2002, three composite surface soil samples were collected from each location CK, SPP, CFP, TCP and NSF. A composite sample is a mix of ten individual samples $\left(25 \times 25 \mathrm{~cm}^{2}\right)(0-20 \mathrm{~cm}$ depth $)$ taken randomly 5$10 \mathrm{~m}$ apart, and kept in plastic bags on ice for transport to the laboratory. The soil samples were stored in the laboratory at $4{ }^{\circ} \mathrm{C}$ and biological assays were conducted within $48 \mathrm{~h}$. The residual soil was air-dried and analyzed for chemical properties. Before chemical and biological analysis, the soil samples were sieved to pass $2 \mathrm{~mm}$. The analyses of soil physical properties were conducted in June 2002.

\section{Physical Properties}

Soil bulk density (BD) was determined by the core method. Gravimetric water-holding capacity (WHC) of soil was measured by the tube method. Soil particle size analysis was done by the hydrometer method. Total porosity was calculated according to determined particle density. The infiltration rate (IR) of the soil was measured by using a double-ring metallic infiltrometer with a $35.5 \mathrm{~cm}$ outer diameter and a $12.4 \mathrm{~cm}$ inner diameter as described by Editorial Committee (1996).

\section{Chemical Properties}

Soil $\mathrm{pH}$ was determined in 1:2.5 soil-water slurry using a combination glass electrode. Soil organic carbon (SOC) was determined by the oil bath- $\mathrm{K}_{2} \mathrm{Cr}_{2} \mathrm{O}_{7}$ titration method. Total nitrogen (TN) was determined by the semi-micro Kjeldahl method. Available nitrogen (AN) was determined by a micro-diffusion technique after alkaline hydrolysis. Total phosphorus (TP) was determined colorimetrically after wet digestion with $\mathrm{H}_{2} \mathrm{SO}_{4}+\mathrm{HClO}_{4}$. 
Available phosphorus (AP) was exacted with $0 \cdot 5 \mathrm{~mol}^{-1} \mathrm{NaHCO}_{3}$ solution ( $\mathrm{pH} 8 \cdot 5$ ). Phosphate-P in solution was determined colorimetrically by the formation of the blue phosphomolybdate complex following reduction with ascorbic acid. Total potassium (TK) was determined by the Cornfield method. Available potassium (AK) was determined by $\mathrm{CH}_{3} \mathrm{COONH}_{4}$ extraction method (Editorial Committee, 1996). The exchangeable cations $\left(\mathrm{K}^{+}\right.$, $\mathrm{Na}^{+}, \mathrm{Ca}^{2+}, \mathrm{Mg}^{2+}$ ) were extracted from the soil with normal neutral ammonium acetate. $\mathrm{K}^{+}$and $\mathrm{Na}^{+}$in solution were determined flamephotometrically. $\mathrm{Ca}^{2+}$ and $\mathrm{Mg}^{2+}$ in the leachate were analyzed by AAS. Microbial biomass was determined by the chloroform fumigation method ( $\mathrm{Li}$ et al., 1996), using a Kc $=0 \cdot 45$.

\section{Metabolic Properties}

The metabolic diversity patterns were measured by using Biolog Microstation System ${ }^{\circledR}$ (Biolog, Inc., Hayward, CA). A sample of $10 \mathrm{~g}$ of soil were shaken for $15 \mathrm{~min}$ with $95 \mathrm{ml}$ of sterile $0 \cdot 145 \mathrm{M} \mathrm{NaCl}$. Soil samples were serially diluted to $10^{-3}$, and $125 \mu \mathrm{l}$ of the $10^{-3}$ suspension was inoculated into each well of a GN-BIOLOG plate. Plates were incubated at $25^{\circ} \mathrm{C}$, and well absorbance values were read at $590 \mathrm{~nm}$ with a $\mathrm{BIOLOG}{ }^{\mathbb{R}}$ microplate reader at $4 \mathrm{~h}$ intervals after inoculation until $240 \mathrm{~h}$.

\section{Average Well Color Development (AWCD)}

The average well colour development (AWCD) reflects the sole-carbon-source utilization ability of the soil microbial community and it was also an important indicator reflecting microbial activity. It was calculated for each microplate following Garland (1996). A reference point of 0.6 AWCD was used to compare BIOLOG ${ }^{\circledR}$ substrate utilization patterns, except for the control. The $240 \mathrm{~h}$ AWCD of the control was used for comparison because it was so low.

\section{Substrate Richness Index (RI) and Shannon's Diversity Index (SI)}

BIOLOG $^{\circledR}$ substrate-utilization patterns can indicate the changes in soil microbial community composition caused by different management practices. The changes in the metabolic profile of this community can be used as a rapid indicator of the effect of management on soil quality (Bending et al., 2000). Substrate richness (the number of substrates utilized) and Shannon's diversity index were analyzed according to Zak et al. (1994).

\section{Soil Quality Index (QI)}

Previous studies have concentrated on evaluation of single soil properties, such as changes in soil organic matter, $\mathrm{N}, \mathrm{P}$ and $\mathrm{K}$, and much less attention has been paid to a comprehensive assessment of soil quality change. The calculated integrated soil quality index $(Q I)$ intends to reflect the relative soil quality degree of different vegetation types. In this study the soil quality index was determined by a formula adapted from Fu et al. (2004).

$$
Q I=\sum_{i=1}^{n}\left(W_{i} \times Q\left(x_{i}\right)\right)
$$

Where $W_{i}$ is the weight vector of $i$ soil quality factor and $Q\left(x_{i}\right)$ is the scoring result of each soil quality factor.

The scoring results $\left(Q\left(x_{i}\right)\right)$ were calculated by the ascending and descending functions listed below (equations 2 and 3). A descending function was used for bulk density (BD) as its higher value often indicated soil deterioration, while an ascending function was used for soil nutrients and microbial functions.

$$
\begin{aligned}
& Q\left(x_{i}\right)=\left(x_{i j}-x_{i \min }\right) /\left(x_{i \max }-x_{i \min }\right) \\
& Q\left(x_{i}\right)=\left(x_{i \max }-x_{i j}\right) /\left(x_{i \max }-x_{i \min }\right)
\end{aligned}
$$

Where $x_{i j}$ is the value of the soil's physicochemical and biological properties that were selected for the soil quality; $x_{i \max }$ and $x_{i \min }$ are the maximum and minimum value of the $i$ soil property. 
In this study, the weights for each indicator were determined by the principal component analysis (PCA) method (Fu et al., 2004).

\section{Statistical Analysis}

One-way analysis of variance (ANOVA) procedures were used to compare the effects of forest restoration approaches on physical, chemical and biological properties of soil. Values of soil properties that differed at $P<0.05$ were considered significant trends. All the analyses were conducted through the SPSS ${ }^{\circledR}$ program.

\section{RESULTS}

\section{Soil Physical Properties}

The soils of plantations and control were considerably lower in silt and slightly lower in clay than adjacent soils under natural secondary forest. Accordingly, the sand content was the lowest in the soils under natural secondary forest and significantly different from that of other sites.

Control soils had the highest bulk density (BD). There were no significant differences for soil bulk density among the three plantations. The values of porosity were contrary to that of bulk density.

The trend of water holding capacity (WHC) was the same as that of infiltration rate (IR). The soils under natural secondary forest had the highest level, while values of the two indicators were the lowest for the soils of control sites. But there exists no significant difference for the above indicator among between the three plantations.

Leaf litter fall was highest in natural secondary forest and almost nil in control areas.

Control soils are least acidic and slash pine soil most acidic. See Figure 1.

\section{Soil Chemical Properties}

Soil organic carbon (SOC) content was significantly higher in natural secondary forest than that of plantations and control. Total nitrogen (TN) and total phosphorus (TP) had the same trend, as well as available $\mathrm{N}$ and available $\mathrm{K}$. But total potassium (TK) does not follow the trend.

Of the exchangeable cations, the greatest variance is in $\mathrm{Ca}^{2+}$. Soils under slash pine and tea-oil camellia plantations have lower $\mathrm{Ca}^{2+}$ content, and their contents were significantly different from those of other sites. But $\mathrm{Mg}^{2+}$ levels under different forest types are not significantly different.

Effective cation exchange capacity (ECEC) was highest in natural secondary forest soils; replanting slash pine and tea-oil camellia resulted in a highly significant lowering of ECEC compared with the adjoining Chinese fir and natural secondary forest soils. However, control soils had higher ECEC. See Figure 2.

\section{Soil Biological Properties}

As an important indicator reflecting sole-carbon-source utilization ability, the values of AWCD were ranked as follows: natural secondary forest $>$ tea-oil camellia plantation $>$ Chinese fir plantation $>$ slash pine plantation $>$ control. See Figure 3.

The carbon content of microbial biomass in natural secondary forest soils had the highest level and was significantly different from that of other sites. There were no significant differences between plantations. The richness and Shannon's diversity indices of utilized substrates in natural secondary forest were the highest and significantly different from those of Chinese fir plantation, slash pine plantation and the control site. The two indices and the content of microbial biomass carbon were significantly lowest in the control sites (see Figure 4).

\section{Soil Quality Index (QI)}

The standardized data of selected indicators and the weights for each indicator were determined following Fu et al. (2004) (see Table I).

The scored indicators were further combined into soil quality index. The $Q I$ values for control, slash pine plantation, Chinese fir plantation, tea-oil camellia plantation and natural secondary forest were $0 \cdot 04,0 \cdot 36,0 \cdot 55$, 

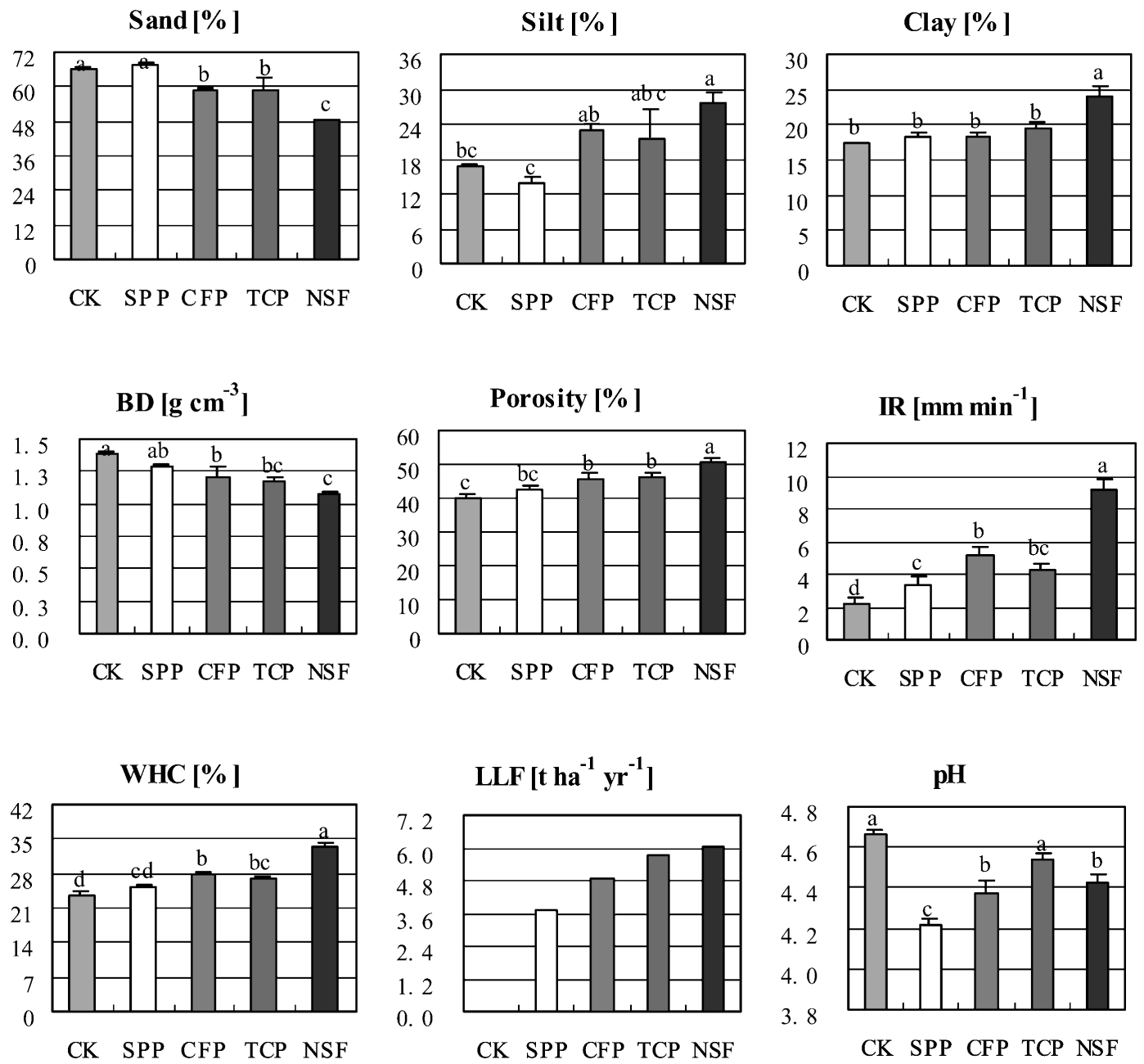

Figure 1. Effects of different forest restoration approaches on selected physical properties, leaf litter fall* and soil $\mathrm{pH}$ values (0-20 cm depth) of adjacent areas of similar soils in Changchong Valley, Hunan Province.

Note: $\mathrm{CK}=$ control; $\mathrm{SPP}=$ slash pine plantation; $\mathrm{CFP}=$ Chinese fir plantation; $\mathrm{TCP}=$ tea-oil camellia plantation; $\mathrm{NSF}=$ natural secondary forest; $\mathrm{BD}=$ bulk density; $\mathrm{WHC}=$ water holding capacity; $\mathrm{IR}=$ infiltration rate; $\mathrm{LLF}=$ leaf litter fall. Bars denote the standard error of mean. Treatments with different letters indicate significant difference $(p<0 \cdot 05)$.

$* 1 \times 1 \mathrm{~m}^{2} ;$ Litter tramps $n=18$ (Yuan et al., 2003).

0.68 and 0.95 , respectively (Figure 5). These soil quality indices clearly show that obvious differences occur in the soil quality when restored naturally and replanted with slash pine, Chinese fir and tea-oil camellia in hilly red soil regions, Southern China. In contrast, the quality index for soils under natural secondary forest was higher than that of other sites, which indicated that natural restoration could improve soil quality more effectively. Among plantations, soil quality under tea-oil camellia with less disturbance were better than that under Chinese fir and slash pine plantations with periodical tending. Long-term disturbances degrade soil conditions severely in control sites.

\section{DISCUSSION}

Different reforestation approaches resulted in remarkable differences in soil physicochemical and biological properties. The differences probably resulted from the following factors shown in Fig. 2: 


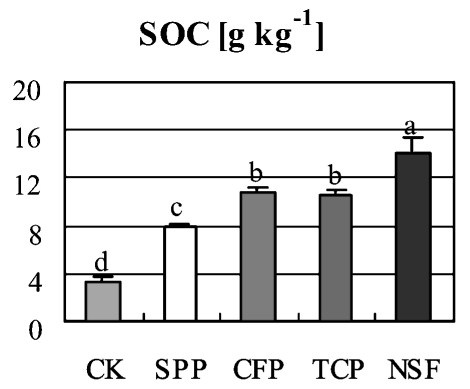

TK $\left[\mathrm{g} \mathrm{kg}^{-1}\right.$ ]

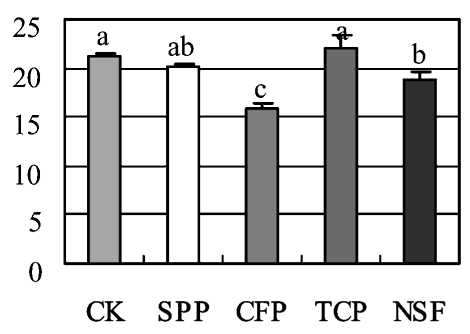

AK [mg kg ${ }^{-1}$ ]

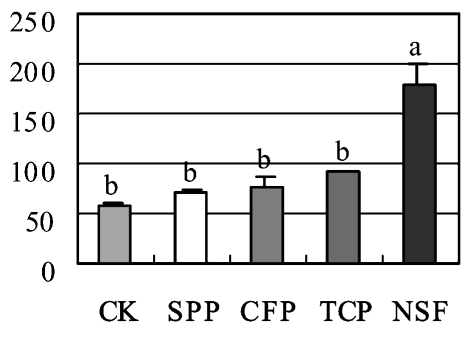

$\mathrm{K}^{+}\left[\mathrm{cmol}+\mathbf{k g}^{-1}\right]$

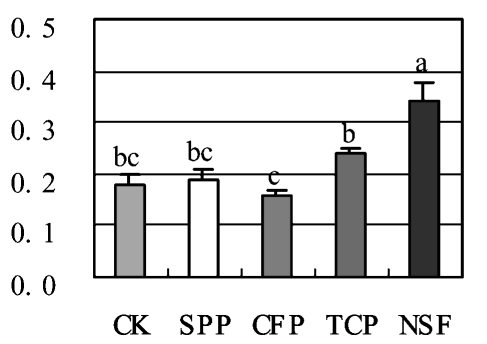

TN $\left[\mathrm{g} \mathrm{kg}^{-1}\right.$ ]

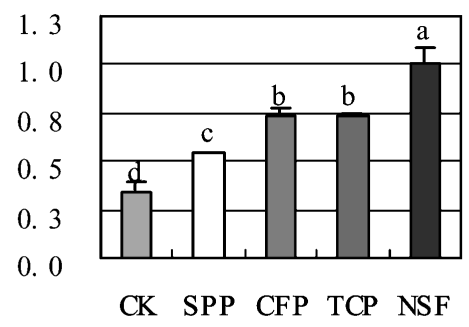

AN [mg kg ${ }^{-1}$ ]

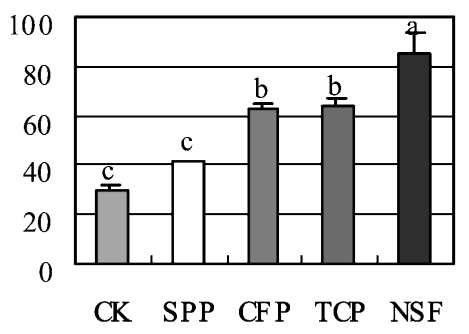

$\mathrm{Ca}^{2+}\left[\mathrm{cmol}+\mathrm{kg}^{-1}\right]$

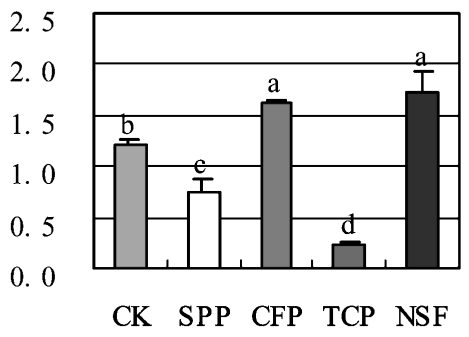

$\mathrm{Na}^{+}\left[\mathrm{cmol}+\mathrm{kg}^{-1}\right]$

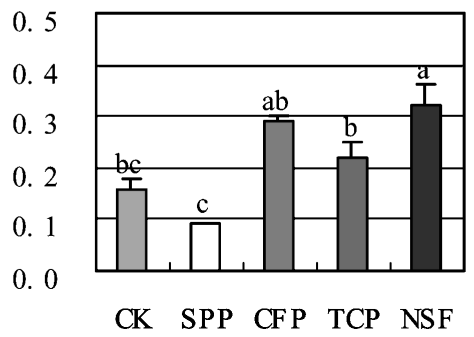

TP [g kg $\left.{ }^{-1}\right]$

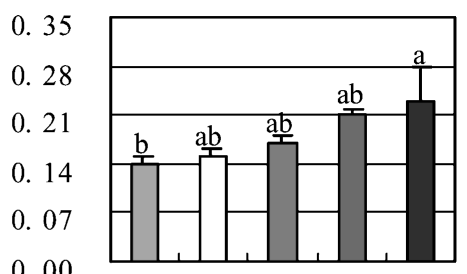

CK SPP CFP TCP NSF

AP [mg kg ${ }^{-1}$ ]

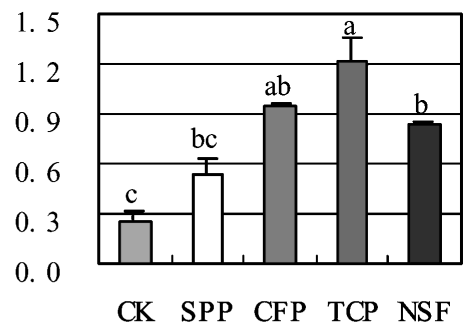

$\mathrm{Mg}^{2+}\left[\mathrm{cmol}+\mathrm{kg}^{-1}\right]$

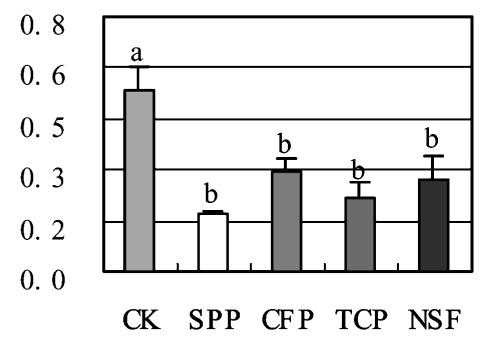

ECEC [cmol $\left.+\mathrm{kg}^{-1}\right]$

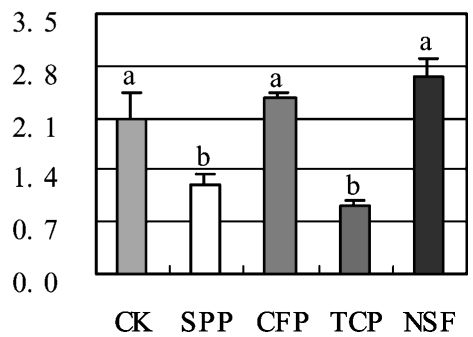

Figure 2. Effects of different forest restoration approaches on selected chemical properties $(0-20 \mathrm{~cm}$ depth) of adjacent areas of similar soils in Changchong Valley, Hunan Province.

Note: $\mathrm{CK}=$ control; $\mathrm{SPP}=$ slash pine plantation; $\mathrm{CFP}=\mathrm{Chinese}$ fir plantation; $\mathrm{TCP}=$ tea-oil camellia plantation; $\mathrm{NSF}=$ natural secondary forest $\mathrm{SOC}=$ soil organic carbon; $\mathrm{TN}=$ total nitrogen; $\mathrm{TP}=$ total phosphorus; $\mathrm{TK}=$ total potassium; $\mathrm{AN}=$ available nitrogen; $\mathrm{AP}=$ available phosphorus; $\mathrm{AK}=$ available potassium; $\mathrm{ECEC}=$ effective cation exchange capacity. Bars denote the standard error of mean. Treatments with different letters indicate significant difference $(p<0 \cdot 05)$. 


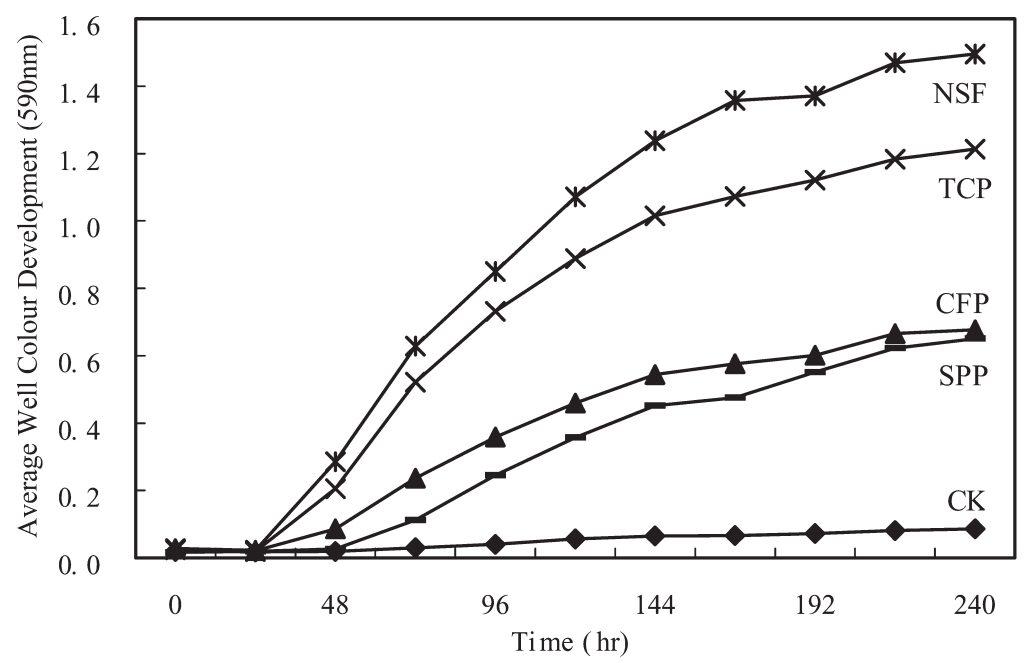

Figure 3. Average well color development (AWCD) of microbial community in $0-20 \mathrm{~cm}$ soil.

Note: $\mathrm{CK}=$ control; $\mathrm{SPP}=$ slash pine plantation; $\mathrm{CFP}=$ Chinese fir plantation; $\mathrm{TCP}=$ tea-oil camellia plantation; $\mathrm{NSF}=$ natural secondary forest.

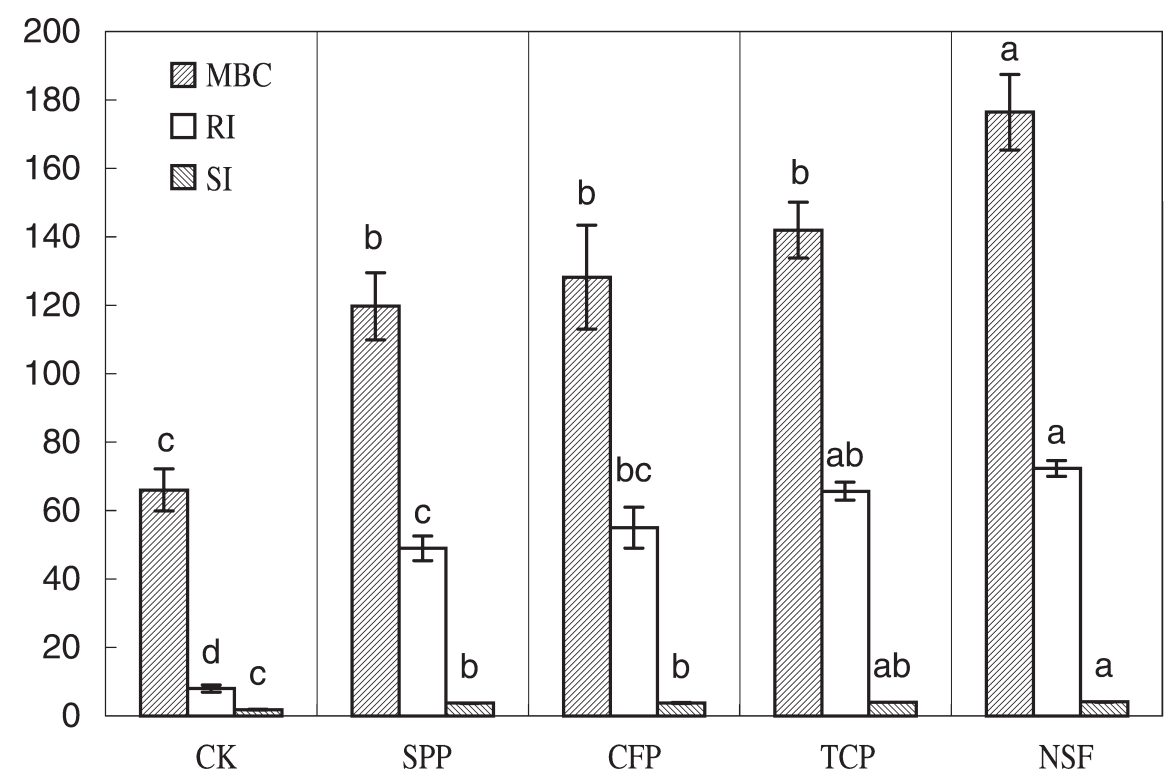

Figure 4. Effects of different forest restoration approaches on selected biological properties $(0-20 \mathrm{~cm}$ depth $)$ of adjacent areas of similar soils in Changchong Valley, Hunan Province.

Note $: \mathrm{MBC}=$ microbial biomass carbon $\left[\mathrm{mg} \mathrm{kg}^{-1}\right] ; \mathrm{RI}=$ richness index; $\mathrm{SI}=$ Shannon's index; $\mathrm{CK}=$ control; $\mathrm{SPP}=$ slash pine plantation; $\mathrm{CFP}=$ Chinese fir plantation; $\mathrm{TCP}=$ tea-oil camellia plantation; $\mathrm{NSF}=$ natural secondary forest. Bars denote the standard error of mean . Treatments with different letters indicate significant difference $(p<0 \cdot 05)$ in the same series.

\section{Improper Artificial Tending}

During reforestation artificial tending was an effective approach to make the forest close earlier and accelerate plant growth, which was the initial motive in forest restoration. But artificial tending may be the main reasons for decreasing soil organic matter and deteriorating soil structure. On-the-one-hand, loosening the soils all over the 
Table I. Indicator scoring results through transforming data and weight for soil quality indices calculation

\begin{tabular}{|c|c|c|c|c|c|c|c|c|c|c|c|c|c|}
\hline $\begin{array}{l}\text { Forest } \\
\text { types }\end{array}$ & $\mathrm{BD}$ & WHC & SOC & $\mathrm{TN}$ & $\mathrm{TP}$ & TK & AN & $\mathrm{AP}$ & $\mathrm{AK}$ & ECEC & MBC & RI & SI \\
\hline n & & 0.000 & & & & & & & & & & 00 & 0.000 \\
\hline PP & & & & & & & & & & & & & 0.837 \\
\hline FP & J & 0 & $0 \cdot 6$ & & & & & & & & $0 \cdot 5$ & & $0 \cdot 860$ \\
\hline & & & & & & & & & & & & & 0.966 \\
\hline & & & & & & & & & & & & & 1.000 \\
\hline Weight & 0.092 & $0 \cdot 086$ & 0.092 & 0.092 & 0.083 & 0.033 & 0.092 & 0.069 & 0.079 & 0.023 & 0.091 & 0.087 & 0.080 \\
\hline
\end{tabular}

Note: $\mathrm{CK}=$ control; $\mathrm{SPP}=$ slash pine plantation; $\mathrm{CFP}=$ Chinese fir plantation; $\mathrm{TCP}=$ tea-oil camellia plantation; $\mathrm{NSF}=$ natural secondary forest; $\mathrm{BD}=$ bulk density; $\mathrm{WHC}=$ water holding capacity; $\mathrm{SOC}=$ soil organic carbon; $\mathrm{TN}=$ total nitrogen; $\mathrm{TP}=$ total phosphorus; $\mathrm{TK}=$ total potassium; $\mathrm{AN}=$ available nitrogen; $\mathrm{AP}=$ available phosphorus; $\mathrm{AK}=$ available potassium; $\mathrm{ECEC}=$ effective cation exchange capacity; $\mathrm{MBC}=$ microbial biomass carbon; $\mathrm{RI}=$ richness index; $\mathrm{SI}=$ Shannon's diversity index.

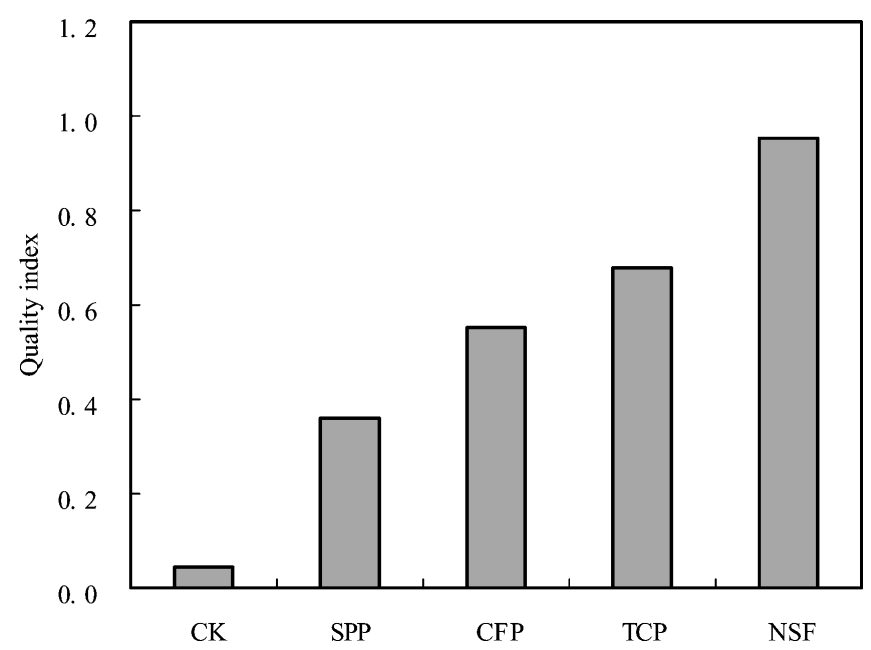

Figure 5. Soil quality index for different forest types in Changchong Valley, Hunan Province.

Note: $\mathrm{CK}=$ control; $\mathrm{SPP}=$ slash pine plantation; $\mathrm{CFP}=$ Chinese fir plantation; $\mathrm{TCP}=$ tea-oil camellia plantation; $\mathrm{NSF}=$ natural secondary forest.

ground breaks up macroaggregates and exposes previously protected organic matter in soil macroaggregates during artificial tending, including land shaping; on the other hand, it accelerated the mixing of organic residues and soils. Thus, soil organic carbon under plantations has less physical protection than that of natural secondary forest. Due to the mixture of organic residues and soil and the enhanced microbial activity, part of the organic matter was decomposed, resulting in a decline in soil structural properties and an increase in bulk density (Blair et al., 1995). Higher bulk density and lower organic carbon content in plantation soils may partly result from periodic tending and land shaping, compared with natural secondary forest soil.

According to Allen (1985), soil compaction commonly results in a decline in macroporosity, high susceptibility to erosion and decreased hydraulic conductivity. These were represented in this study. For instance, bulk density, water holding capacity, infiltration rate and porosity of control and plantation soils were also lower than those of natural secondary forest soils.

Consequently in the early stage of forest restoration, altering the above method of artificial tending may be more effective in protecting soil, for example loosening the soil around the base of the trees only instead of loosening the soil all over the ground. 


\section{Soil Erosion}

Soil and water loss was an important factor influencing soil properties. Based on five-years' observation, Tian et al. (2002) reported that in five vegetation types the severe degree of soil and water loss was ranked as follows: control $>$ slash pine plantation $>$ Chinese fir plantation $>$ tea-oil camellia plantation $>$ natural secondary forest. The effect of controlling soil and water loss was most obvious in natural secondary forest.

The soils of plantation and control were considerably lower in silt and slightly lower in clay than adjacent soils under natural secondary forest, most likely as the results of preferential removal of silt and clay by accelerated water erosion (Hassan and Majumder, 1990). Greater residual sand content combined with decreased porosity probably accounts for the higher bulk density and poorer water-holding capacity of soils under plantation and control in comparison with natural secondary forest.

Soil and water loss are often associated with soil nutrient loss. In plantations, lower soil organic carbon, total nitrogen, total phosphorus, available nitrogen, and available potassium may be partly due to more severe soil and water loss.

As soil organic carbon is an important carbon source for the soil microbial community, the loss of soil organic carbon would further influence the soil microbial community indirectly. The loss of this carbon source would also decrease the amount and sort of soil microbes, as was reflected by the indicators of microbial biomass carbon, utilized substrate richness and Shannon's diversity indices (see Figure 4).

Both the microbial biomass carbon and the average well-colour development, functional diversity indices were dominant in natural secondary forest, compared with that in plantations and control sites (see Figures 3 and 4). Based on the consistent soil situation in four forest types and control, control and plantations not only reduced microbial biomass carbon, but also decreased the microbial populations that could utilize certain sorts of carbon source (expressed by the richness index, see Figure 4) and the ability to utilize sole-carbon-source for the microbial community (expressed by AWCD), compared with natural secondary forest. Natural restoration was more propitious in improving the structure and function of the soil microbial community.

\section{Litter Fall}

Litter production was an important factor influencing the structure and function of the soil microbial community. Its enhanced structure and function for tea-oil camellia plantation and natural secondary forest probably relates to their higher quality litter fall and higher litter fall production. Yuan et al. (2003) reported that in tea-oil camellia plantation and natural secondary forest over 70 per cent of the total leaf litter fall was easily decomposed broad leaf; natural secondary forest and tea-oil camellia plantation were more effective in adjusting microclimate within the forest. Poor soil structure due to tending methods and severe land use causing soil erosion also degrades the living conditions of the soil microbial community in plantations and control sites respectively.

In addition, litter fall composition and decomposition also further influences nutrient cycle. The lower levels of total organic carbon in plantations and control sites mainly result from lower-quality litter fall and lower litter production (see Figure 1). In slash pine and Chinese fir plantations, 82.90 per cent and 69.95 per cent of the total leaf litter fall were hard decomposed needle leaves of slash pine and Chinese fir respectively (Yuan et al., 2003).

The lowest total potassium content in Chinese fir plantation soil mainly results from the highest content of total potassium in Chinese fir $\left(2.42 \mathrm{mg} \mathrm{kg}^{-1}\right)$. Moreover, 69.95 per cent of the total leaf litter fall was hard decomposed needle leaf of Chinese fir (Yuan et al., 2003).

Litter fall decomposition also influences soil $\mathrm{pH}$. The soils under slash pine plantation were significantly more acidic than those of other sites. The litter-fall decomposition and root exudates of slash pine are the likely contributing factors to the naturally very acid $\mathrm{pH}$ levels in these soils. Among the leaf litter fall, 82.9 per cent of this was hard decomposed needle leaf of slash pine and the decomposition of such litter could produce a great deal of organic acid (Yuan et al., 2003).

\section{Interactions of Soil Indicators}

Brubaker et al. (1993) reported that soil organic matter could influence nutrient retention and supply. The similar trend between soil carbon and total nitrogen content may be the result of this. The trends of available nitrogen and 
available potassium are also consistent with that of total organic carbon. Besides being correlated with soils' organic matter influencing nutrient retention and supply, this probably relates to biological activities of soils (see Figures 3 and 4) as the soil microbial community improves the availability of soil nutrients.

Less difference of total phosphorus among the ecosystems may be due to the inactive nature of phosphorus, especially in acidic conditions (Li et al., 1995).

Among different forest types, less difference for $\mathrm{Mg}^{2+}$ is probably due to the mineralogical composition of these soils, while higher exchangeable $\mathrm{Ca}^{2+}$ and $\mathrm{Mg}^{2+}$ contents in control sites may relate to the highest $\mathrm{pH}$ level (Li et al., 1995).

\section{CONCLUSION}

Significant differences between forest restoration approaches were found for soil biological, chemical and physical properties. Whether in natural secondary forest through natural restoration or in plantations, soil quality was obviously improved in comparison with control sites that were disturbed frequently. In the plantations indicators of soil physicochemical and biological properties had lower levels than those in the natural secondary forest, but bulk density was higher. Compared to replanting with slash pine, Chinese fir and tea-oil camellia, natural restoration is the most beneficial way to improve soil quality and regenerate degraded lands.

\section{ACKNOWLEDGEMENTS}

We acknowledge the financial supporting of the National Key Basic Research Program (G2000046807), the National Natural Science Foundation of China (30230090) and the Knowledge Innovation Project of Chinese Academy of Sciences (KZCX2-405). We also thank Prof. Z.K. Yuan, Prof. X.Q. Li and D.L. Jiang for help in experimental investigation and sampling.

\section{REFERENCES}

Allen J. 1985. Soil response to forest clearing in the United States and in the tropies: geological and biological factors. Biotropica 11: 15-21.

Bending GD, Putland C, Rayns F. 2000. Changes in microbial community metabolism and labile organic matter fractions as early indicators of the impact of management on soil biological quality. Biology and Fertility of Soils 31: 78-84.

Blair GJ, Lefroy RDB, Lise L. 1995. Soil carbon fractions based on their degree of oxidation, and the development of a carbon management index for agricultural systems. Australian Journal of Agricultural Research 46: 1459-1466.

Brubaker SC, Johnes AJ, Lewis DT, Frank K. 1993. Soil properties associated with landscape positions. Soil Science Society of American Journal 57: 235-239.

Editorial Committee. 1996. Soil Physical and Chemical Analysis and Description of Soil Profiles. Standards Press of China: Beijing. (In Chinese.)

Fu BJ, Liu SL, Chen LD, Lü YH, Qiu J. 2004. Soil quality regime in relation to land cover and slope position across a highly modified slope landscape. Ecological Research 19: 111-118.

Garland JL. 1996. Analytical approaches to the characterisation of sample microbial communities using patterns of potential C source utilisation. Soil Biology \& Biochemistry 28: 213-221.

Hassan MM, Majumder AH. 1990. Distribution of organic matter in some representative forest soils of Bangladesh. Indian Journal of Forestry 13: $281-287$.

Li FD, Yu ZN, He SJ (eds). 1996. Agricultural Microbiology Experimental Technique. Press of Chinese Agriculture: Beijing; 82-83. (In Chinese.)

Li ZA, Fang W, Lü DM. 1995. Physical and chemical properties of soils in Heshan hilly land. Acta Ecologica Sinica 15(Suppl. A): 93-102. (In Chinese with English abstract.)

Tian YX, Li XQ, Yuan ZK, He YJ, Chen XP, Ni AP. 2002. Studies on benefit of soil and water conservation of different forest types in red soil regions of South Hunan. Research of Soil and Water Conservation 9(4): 80-82. (In Chinese with English abstract.)

Xie Y. 2002. Restoring Chinese Natural Vegetation. Chinese Forestry Press: Beijing; 7-11. (In Chinese.)

Yuan ZK, Lang NJ, Wu QX. 2003. Configured Techniques of Protection Forest System Construction in Altiplano and Hilly Region of Yangze River Mid-Low Reaches_-Study and Demonstration. Hunan Science and Technology Press: Changsha; 131-133. (In Chinese with English abstract.)

Zak JC, Willig MR, Moorhead DL, Wildman HG. 1994. Functional diversity of microbial communities: a quantitative approach. Soil Biology \& Biochemistry 26: 1101-1108.

Zhao QG (ed.). 2002. The Red Soil Material Cycling and its Regulation. Science Press: Beijing. (In Chinese with English summary.) 